\title{
Participatory Rural Appraisal to Detect Childhood Blindness in Community
}

\author{
Amarendra Deka ${ }^{1}$, Jacqueline S Syiem², S P Saikia ${ }^{1}$, Valensha Surong ${ }^{1}$
}

\section{Amarendra Deka', Jacqueline S Syiem ${ }^{2}$, S P Saikia', Valensha Surong ${ }^{1}$ \\ 'Department of Ophthalmology, Affilia- tion Mission Nethralaya, Shillong, India ${ }^{2}$ Civil Hospital, Shillong, Megahlaya, India}

Correspondence

\section{Dr Amarendra Deka}

Missioni Nethralaya, Rum Jingkieng. Nongthymmai, Shillong 793014, Meghalaya, INDIA.

Mobile no: +91-9206011040

Email: mintu_deka@yahoo.co.in

History

- Submission Date: 18-11-16

- Revised Date: 17-01-17

- Accepted Date: 18-03-17

DOI : 10.5530/ijmedph.2017.2.16

Article Available online

http://www.ijmedph.org/v7/i2

Copyright

(C) 2017 Phcog.Net. This is an openaccess article distributed under the terms of the Creative Commons Attribution 4.0 International license.

\begin{abstract}
Introduction: To evaluate the role of participatory rural appraisal (PRA) in community based rehabilitation (CBR) to detect and manage childhood blindness from rural community. Methods: Fifteen rural project areas with pre-existing CBR project were shortlisted. Main criteria of this selection were pre-existing CBR project with significant number of children with visual impairment. We have adopted PRA methodology to reach the rural community whilst aiming to detect childhood blindness. PRA approaches were also utilized to achieve immunization, spacing between child birth, proper maternal and child health and overall improvement of lifestyle. Information about the villages was collected from villagers by social mapping performed by the villagers themselves. Student's t test was used to analyze the result. Results: 128 children (CBR program) with visual disability were identified out of which $77.14 \%$ were blind and $22.86 \%$ had SVI. After adopting PRA approach 84 new cases $(p<0.05 \%)$ were detected of which $71.43 \%$ were blind and $28.57 \%$ had SVI. Main causes of blindness were cornea related $(31.28 \%)$, lens related (21.72\%) and buphthalmos (17\%). Immunization of child improved from $11 \%$ to $81 \%$ ( $p=0.011$ ) over a period of one year. Common practices including food habit, spacing between child births improved. $41 \%$ children are mobilized to blind school for rehabilitation. Conclusion: PRA methodology is a new approach in community ophthalmology and is very promising to detect and rehabilitate visually impaired children. PRA is very useful to improve knowledge, to plan rehabilitation as well to treat underlining causes of childhood blindness.
\end{abstract}

Key words: Participatory Rural Appraisal, Childhood blindness, Community, Social mapping, Immunization

\section{INTRODUCTION}

Public health in developing countries is a strange paradox. Because majority of health resources are located in urban area where less population lives whereas less health resources are located in rural area where more of the population lives. Due to absence of quality primary healthcare and low awareness among poor on availing such care, they are availing care from dubious sources or foregoing care leading to rise in morbidity and mortality in the rural community.

Participatory Rural Appraisal (PRA) is an interactive approach in research that emphasizes local participation, which enables local people to contribute in their own appraisal, analysis and plans. PRA aims to facilitate information sharing among stakeholders. The objective of PRA is to enable development workers, government officials, and local people to work together to plan appropriate programs. PRA in not new in development process. It has evolved from Rapid Rural Appraisal (RRA) and has been implemented in several development projects. ${ }^{1}$ However, its uses in community ophthalmology as an alternative methodology is limited.

As we are aware of the fact that about 1.4 million blind children in the world ${ }^{2}$. Every minute, somewhere in the world, a child goes blind and nearly half a million children develop blindness each year. Ninety per cent of blind children die before reaching adulthood usually from malnutrition. It also has been estimated that nearly a third of the global economic cost of blindness is due to childhood blindness. However, positive aspect of childhood blindness is about 45 percent of blindness in these children could have been prevented or treated. Present existing approaches are very effective to diagnosing childhood blindness from the community. However, impact of these approaches in the society is debatable. Despite implementation of several approaches in the rural community, it has been observed that prevalence of childhood blindness is not significantly decreasing.

This is the vicious circle of poverty and poor health and it does exist in rural areas of developing countries like India. Presently all community approaches 


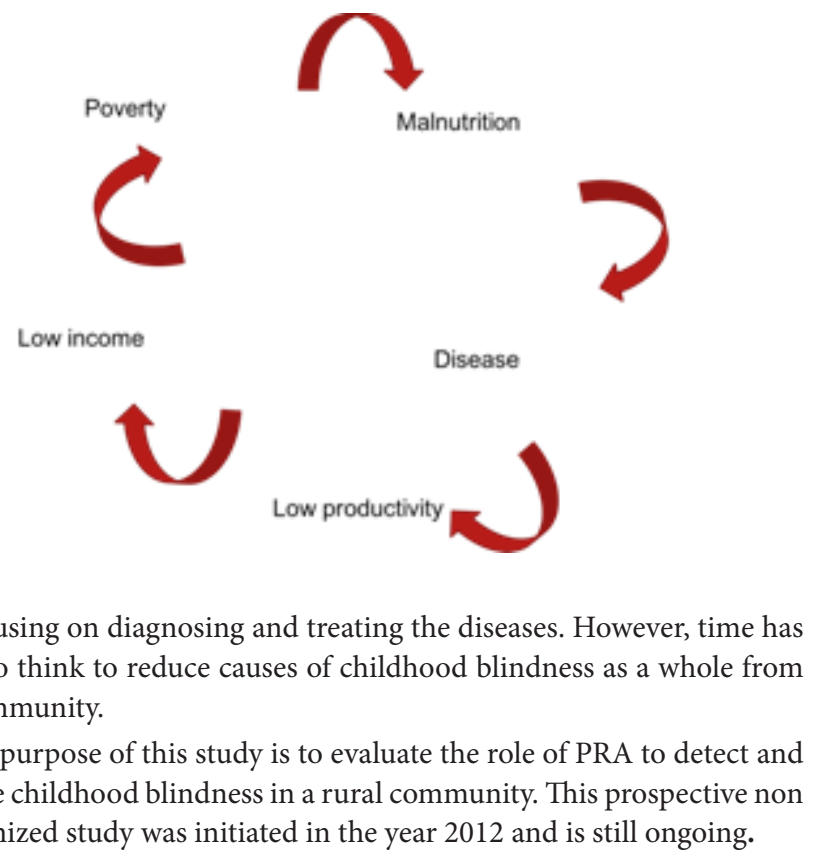

randomized study was initiated in the year 2012 and is still ongoing.

\section{METHOD AND METHODOLOGY}

Fifteen rural villages with pre-existing CBR project are selected. Main criteria of this selection are pre-existing CBR project with significant number of visually impaired children. PRA methodology is adopted to reach out to the rural community to detect childhood blindness, to improve knowledge and general health along with eye care. PRA approaches were also utilized to improve immunization, spacing, proper maternal \& child health and overall improvement of lifestyle. WHO classification of blindness is used to categorize the cases. Student's t test is used to analyze the result.

First step of the PRA approach is site selection and preliminary site visit. The villages were selected based on certain criteria like distance from base hospital, size of villages and socioeconomic status. However, foremost important criterion for selection is active participation by the villagers for the PRA activities. The next step is announcement of activities in the villages and we used locally available resources to spread the information.

Most important step is data gathering regarding child health in the community and social mapping is very suitable to gather information from the villagers (Figure 1). Most villagers took part in social mapping and they used locally available materials like pulse, bangles, stones, toilet papers etc. to denote important structures of the villages. The next step is preparation of action plan, and we visited houses of villagers to know the environment they are living in. Health awareness lectures by a local ophthalmologist from nearby existing health centre were also arranged and conducted. The basic idea to involve the local ophthalmologist is to build relation with the villagers so that they can visit the nearby existing health centre in future for eye care. Besides gathering data on childhood blindness, we also encouraged strategies to improve health. Simple practices like hand washing, safe drinking water, safe disposal of excreta, well ventilated house, proper drainage, use of mosquito nets, vaccination, spacing between child birth, balance diet, rehabilitation etc. can improve the child health in the rural community. We also organised evening free eye check-up camps in each village. As majority of villagers are daily wagers or cultivators, and hence evening eye camp approach was very well accepted. Final step of this approach is monitoring of activities and matrix index which was very useful for this purpose.

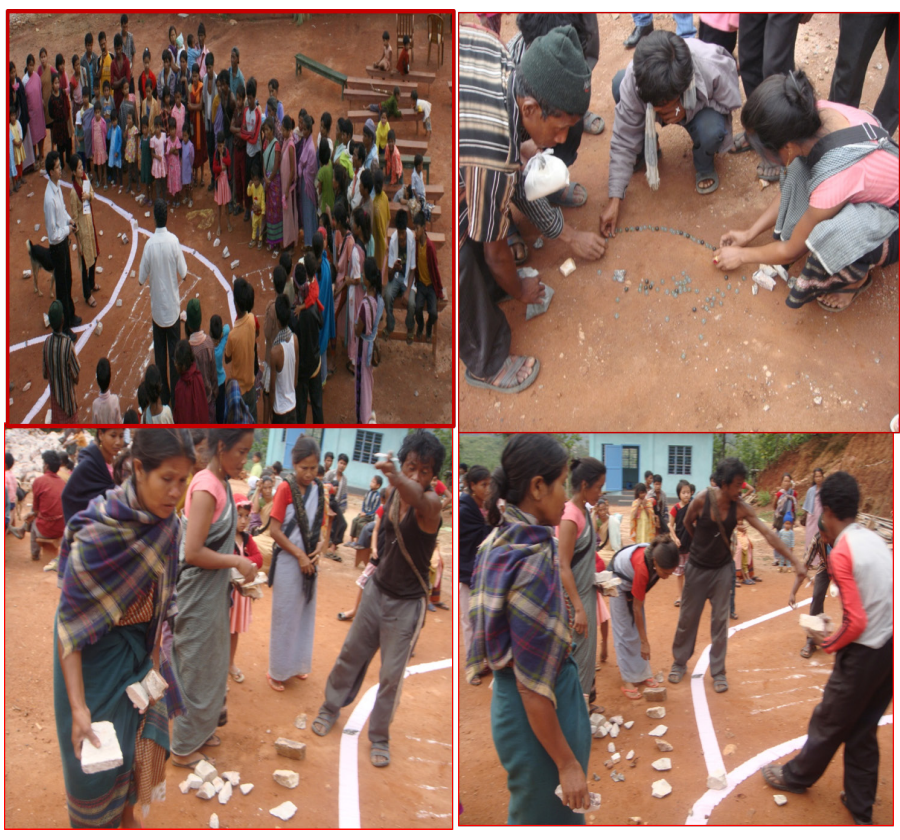

Figure 1: Social mapping to gather information of child health.

\section{Table1: Demographic pattern.}

$\begin{array}{lcc}\text { Age group } & \text { Sex } & \text { Total No } \\ & \text { Girl } & 2970 \\ 0-16 \text { years } & \text { Boy } & 2767 \\ & \text { Girl } & 68 \\ \text { Old Cases } & \text { Boy } & 60 \\ & \text { Girl } & 51 \\ \text { New Cases } & \text { Boy } & 33 \\ & \end{array}$

\section{RESULTS}

5737 children of age group 0-16 years were enrolled. Out of which 2970 are girls and 2767 are boys (Table 1). 128 children with visual disability were identified before implementation of this project and out of which $77.14 \%$ were blind and $22.86 \%$ had SVI. After adopting the PRA approach 84 new cases $(\mathrm{p}<0.05 \%)$ are detected of which $71.43 \%$ are blind and $28.57 \%$ has SVI. Main causes of blindness are cornea related in $31 \%$, lens related in $21 \%$, retina related $15 \%$, congenital defect in $11 \%$, buphthalmos in $8 \%$ and unknown in $14 \%$ cases. Matrix ranking shows improvement over a period of 1 year. All three parameters namely eye health, lifestyle of children and utilization of available health care system showed improvement over 1 year after implementation of this approach. Immunization rate improved from $11 \%$ to $81 \%$ ( $p=0.01)$, Spacing between child birth from $12 \%$ to $43 \%(\mathrm{p}<0.05)$. Vision of $9 \%$ blind child improved after intervention. Rehabilitation of blind children is very important as in majority of cases treatment is not possible due to delayed diagnosis and also each blind child has to live prolonged blind years. It is observed that after adaptation of this PRA approach, rehabilitation rate has improved from $11 \%$ during CBR project to $41 \%$ after adopting PRA approach, which was statistically significant. 


\section{DISCUSSION}

Prevalence of blindness in children is lower than in adults. ${ }^{3}$ But, the number of "blind years" due to all causes of blindness in children is almost equal to the number of "blind years" due to cataract in adults. ${ }^{4,5}$ Many of the causes of blindness in children are either preventable or treatable. ${ }^{4}$ WHO classification of blindness as a corrected visual acuity in the better eye of less than $3 / 60$, and severe visual impairment as a corrected acuity in the better eye of less than $6 / 60$ is followed to categorize the cases. ${ }^{4}$ The causes of blindness in children vary widely from region to region. ${ }^{4,5,6}$ Cornea related blindness mostly due to malnutrition and vitamin A deficiency is still rampant in most of the rural area of developing counters. Rehabilitation of non-treatable cases is very essential as they have to live prolong blind years. However, this is still a challenge in most of the backward areas of developing countries due to social stigma and superstitious beliefs. PRA like methodology allows active participation from the local community in the form of voicing their own ideas and concerns, and at the same time expressing their knowledge about the past and present. The local community gets to present their own priorities for development and see their ideas incorporated into development plans.

PRA approaches have developed out of the Rapid Rural Appraisal (RRA) techniques which were first systematized in the late 1970s, and which had become academically respectable by the end of the 1980s. ${ }^{7}$ PRA has three broad advantages in addition to the speed and cheapness like RRA. First, the information it provides tends to be highly accurate. This is partly because, as experience has shown, local people's knowledge of local conditions is often greater than had been supposed, as is their capacity to map, model, estimate, rank, diagram and plan. Second, plans drawn up in a participatory manner by local people are more likely to work than plans drawn up by outsiders. Third, most important of all, the participatory nature of the process is a development benefit in itself, in terms of empowering local people.

PRA can also provide authentic input from the community for the government to plan relevant programs. PRA will establish better linkages between communities, the agencies and institutions involved in rural community development. Therefore, interaction between communities and researchers can reduce the social barriers. ${ }^{1}$

\section{CONCLUSION}

Avoidance or prevention should be the strategy for childhood blindness as treatment is not possible in majority of cases. PRA methodology is a new approach in community ophthalmology and is very promising to detect and rehabilitate visually impaired children. It is very useful to improve knowledge, to plan rehabilitation as well to address underlining causes of childhood blindness.

\section{ACKNOWLEDGEMENT}

We would like to express our deepest gratitude to all members of Mission Trust. Special thanks to Mr. Bremley AB Lyngdoh for his comments and suggestions.

\section{CONFLICT OF INTEREST}

None

\section{ABBREVIATIONS USED}

PRA: Participatory Rural Appraisal; CBR: Community Based Rehabilitation; WHO: World Health Organization.

\section{REFERENCES}

1. Akademika. Participatory Rural Appraisal (PRA): An Analysis of Experience in Darmareja Village, Sukabumi District, West Java, Indonesia. 2012;82(1):15-9.

2. World Health Organization. Preventing blindness in children: report of WHO/ IAPB scientific meeting. Programme for the Prevention of Blindness and Deafness, and International Agency for Prevention of Blindness. Geneva: WHO, 2000 (WHO/PBL/00.77)

3. Dandona R, Dandona L. Childhood blindness in India: a population based perspective $\mathrm{Br} J$ Ophthalmol. 2003;87(3):263-5. https://doi.org/10.1136/ bjo.87.3.263 ; PMid:12598433 PMCid:PMC1771525.

4. Gilbert C, Foster A. Childhood blindness in the context of VISION 2020 - The Right to Sight. Bulletin of the World Health Organization, 2001;79(3):227-32 PMid:11285667 PMCid:PMC2566382.

5. Hornby SJ et al. The causes of childhood blindness in the People's Republic of China: results from 1131 blind school students in 18 Provinces. British Journal of Ophthalmology, 1999:83(8):929-32. https://doi.org/10.1136/bjo.83.8.929 PMid:10413695 PMCid:PMC1723134.

6. Foster A Gilbert C. Epidemiology of childhood blindness. Eye.1992,6(2):173-6 https://doi.org/10.1038/eye.1992.34; PMid:1624040.

7. Heaver R. Participatory rural appraisal: potential applications in family planning, health and nutrition programmes. RRA Notes. 1992:16:13-21. IIED London. PMid:1460837. 